\title{
Intravenous paracetamol infusion versus intramuscular tramadol as an intrapartum labor analgesic
}

\author{
Hema Mohan*, Rekha Ramappa, Sandesh M., Akash B. K.
}

Department of Obstetrics \& Gynaecology, Shimoga Institute of Medical Sciences, Shimoga, Karnataka, India

\author{
Received: 07 October 2015 \\ Revised: 15 October 2015 \\ Accepted: 30 October 2015 \\ *Correspondence: \\ Dr. Hema Mohan \\ E-mail: drhemamohan1@gmail.com
}

Copyright: $\odot$ the author(s), publisher and licensee Medip Academy. This is an open-access article distributed under the terms of the Creative Commons Attribution Non-Commercial License, which permits unrestricted non-commercial use, distribution, and reproduction in any medium, provided the original work is properly cited.

\begin{abstract}
Background: The objective of the study was to compare intravenous paracetamol and intramuscular tramadol as labor analgesics.

Methods: This prospective-randomized study conducted in 200 primigravidae in active labor, distributed into two groups of 100 women each with one receiving intravenous 1,000 mg Paracetamol and other $100 \mathrm{mg}$ intramuscular tramadol. Pain intensity is recorded by McGills scale before, one and $3 \mathrm{~h}$ after drug administration. Perinatal outcome is recorded.

Results: No difference in pain intensity is seen before drug administration. After $1 \mathrm{~h}$ of drug administration, in paracetamol group, $4 \%$ women had horrible pain, and $28 \%$ had distressing pain, while in tramadol group, $30 \%$ women had horrible pain, and $60 \%$ had distressing pain. After $3 \mathrm{~h}$ of drug administration, in paracetamol group, $26 \%$ had distressing pain, while in tramadol group, $50 \%$ women had horrible pain, and $36 \%$ had distressing pain. Labor duration in paracetamol and tramadol group was 4.6 and $6.0 \mathrm{~h}$, respectively. In paracetamol group, nausea is seen in $2.2 \%$ and vomiting in $1.1 \%$, while in tramadol group, nausea is seen in $6.4 \%$ and vomiting in $4.3 \%$.

Conclusions: Intravenous paracetamol is more effective labor analgesic with fewer maternal adverse effects and shortens labor as compared to intramuscular tramadol.
\end{abstract}

Keywords: Intramuscular tramadol, Intravenous paracetamol, Labor analgesic

\section{INTRODUCTION}

Labor pain is among the most excruciating pain experienced by women. Labor pain affects maternal psychology and course of labor causing apprehension, anxiety and stress. Pain during the first stage of labor originates predominantly due to cervical dilatation and uterine muscle wall ischemia leading to lactate accumulation. During the late first stage and second stage of labor, the vagina and perineum form additional sources of pain. The associated increase in sympathetic activity leads to increased oxygen consumption, respiratory alkalosis, and metabolic acidosis which could lead to decreased oxygen being transferred to the fetus. Thus, pain relief during labor is expected to reduce maternal stress and improve maternal and perinatal outcome. Obstetric analgesia and anesthesia have evolved from vague possibility to reality. The non-pharmacological techniques of analgesia include emotional support, relaxed birth environment, psycho-somatic preparation, yoga, acupuncture, and transcutaneous electrical nerve stimulation (TENS). The commonly used and more effective are pharmacological techniques include opioids like pethidine and tramadol though the regional analgesia is gold standard nowadays and routinely used in modern obstetric anesthesia in developed countries. ${ }^{1}$ The newer advances like combined spinal epidurals, low dose epidurals, patient controlled intravenous, inhalational, 
and epidural analgesia have revolutionized obstetric anesthesia. But most of modern obstetric analgesia practices involve participation of expert anaesthesiologist, costly equipment, and continuous monitoring facilities which unfortunately cannot be available in routine obstetric practice in the developing countries where a majority of obstetric services are in the hands of midwives, trained nurses, and non-specialist doctors. In such situations, a method with minimum technicality is desired.

Paracetamol, the mode of analgesic action of which has still not been fully elucidated but probably is a centrally acting drug which inhibits prostaglandin synthesis, has recently been made available as intravenous preparation. ${ }^{2}$

Various studies have proved intravenous paracetamol as effective analgesic agent which is safe, effective, inexpensive, and requires no special monitoring. However, there are no significant trials regarding paracetamol analgesic effect on labor pain in women. If proved to be an effective analgesic agent in labor, paracetamol being inexpensive and simple to administer could be a boon agent of obstetric analgesia in developing countries. Only a few studies have documented safety and efficacy of intravenous paracetamol as a labor analgesic. Tramadol hydrochloride is a centrally acting analgesic opioid. Intramuscular tramadol hydrochloride is commonly used in labor analgesia in developing countries as it is inexpensive; no special monitoring is required and has been widely studied and proved for its safety and efficacy in labor analgesia. ${ }^{3}$ There is no study comparing these two as labor analgesics.

So, we undertook this study with the aim to compare efficacy and safety of single dose $1,000 \mathrm{mg}$ intravenous paracetamol with $100 \mathrm{mg}$ intramuscular tramadol hydrochloride as labor analgesic in primigravidae women during active phase of labor.

\section{METHODS}

The present study was a single-blinded prospectiverandomized study conducted in 100 primigravidae women in Shimoga institute of medical sciences, Shimoga during the period of April 2015 - September 2015. Inclusion criteria were primigravida with full-term pregnancy in the age group 20-30 years with spontaneous onset of labor with single fetus with vertex presentation in active phase of labor. Active phase of labor was described as cervical dilatation more than or equal to 3 $\mathrm{cm}$, cervical effacement more than or equal to $60 \%$ and good uterine contractions. Women with medical disorders, obstetric complications, scarred uterus, clinical evidence of cephalopelvic disproportion, and history of allergy to any opioid or hypersensitivity to the drugs were excluded from the study.
After taking informed consent, the women were randomly distributed in two groups, Paracetamol group50 women and Tramadol group-50 women. All the women in paracetamol group received a $100 \mathrm{ml}$ intravenous infusion containing $1,000 \mathrm{mg}$ of paracetamol single dose over $15 \mathrm{~min}$, and all the women in the tramadol group were given tramadol hydrochloride 100 mg intramuscular single dose in upper and outer quadrant of gluteal region with a $2-\mathrm{ml}$ syringe. Pain intensity before administering drug was recorded by Mc Gills pain intensity scale (Table 1). In all women included in the study, a detailed history, general physical examination, and obstetric examination including vaginal examination were done and all the required investigations carried out. Labor was monitored using a partogram. Measurement of pain relief was done with McGills pain intensity scale after 1 to $3 \mathrm{hrs}$ of drug administration. Fetal monitoring as done using non stress test. Mode of delivery, neonatal outcome, duration of labor, drug delivery interval, and side effects of drugs in the both the groups were noted. Data were described as Mean \pm SD and percentage.

Table 1: McGill pain intensity scale.

\begin{tabular}{|ll|}
\hline Mc Gills scale & Pain intensity \\
\hline 0 & No pain \\
\hline 1 & Mild pain \\
\hline 2 & Discomfort \\
\hline 3 & Distressing \\
\hline 4 & Horrible \\
\hline 5 & Excruciating \\
\hline
\end{tabular}

\section{RESULTS}

The mean age of women in paracetamol group was $22.0 \pm 2.8 \mathrm{yrs}$ and in tramadol group was $22.1 \pm 2.6$ yrs. the difference was not statistically significant between two groups $(\mathrm{p}=0.406)$.

The mean gestational age in paracetamol group was $38.8 \pm 1.0$ weeks and in tramadol group was $38.7 \pm 1$ week. The difference was statistically insignificant between two groups $(\mathrm{p}=0.380)$.

The mean dilatation and effacement of cervix in paracetamol group were $4.1 \pm 0.2 \mathrm{cms}$ and $75 \pm 10 \%$ respectively. In the tramadol group the mean dilatation and effacement of cervix were $4.1 \pm 0.8 \mathrm{cms}$ and $77.0 \pm 10.6 \%$ respectively. The difference was statistically insignificant between two groups $(\mathrm{p}=0.678,0.483)$.

Using McGills pain intensity scale 15 women (30\%) had horrible pain in paracetamol group, 33 women $(66 \%)$ had distressing pain, and 2 women $(4 \%)$ had discomfort at the point of entry into the study. in the tramadol group, 8 women $(16 \%)$ had horrible pain, 39 women $(78 \%)$ had distressing pain and 3 women $(6 \%)$ had discomfort. the pain intensity using McGills scale between two groups 
before drug administration was statistically insignificant $(\mathrm{p}=0.010)$.

After $1 \mathrm{~h}$ of IV paracetamol administration, 2 women $(4 \%)$ had horrible pain and 14 women $(28 \%)$ had distressing pain, and 29 women (58\%) had discomfort, 5 women $(10 \%)$ had mild pain. in tramadol group, 15 women $(30 \%)$ had horrible pain, 30 women $(60 \%)$ had distressing pain, 4 women $(8 \%)$ had discomfort and 1 had (2\%) mild pain after $1 \mathrm{~h}$ of drug administration. the difference was statistically significant between two groups $(\mathrm{p}=0.000)$.

After $3 \mathrm{~h}$ of paracetamol administration, 13 women (26\%) had distressing pain, 20 women (40\%) had discomfort and 17 women $(34 \%)$ had mild pain. in tramadol group, 25 women $(50 \%)$ had horrible pain, 18 women $(36 \%)$ had distressing pain, 4 women $(8 \%)$ had discomfort, 3 women $(6 \%)$ had mild pain, using McGills pain intensity scale. The difference was statistically significant between two groups $(\mathrm{p}=0.000)$.

Women who had LSCS were excluded for comparison of duration of labor. 3 in paracetamol group had LSCS, 4 in tramadol group had LSCS.

The mean duration of the active phase of first stage of labor in the paracetamol group was 212.2 $\pm 30.9 \mathrm{~min}$ $(3.53 \pm 0.51 \mathrm{~h})$ and in tramadol group was $300.2 \pm 30.4 \mathrm{~min}$ $(5.0 \pm 0.5 \mathrm{~h})$. The mean duration of the active phase of first stage of labor between the paracetamol and tramadol groups was statistically significant $(\mathrm{p}=0.000)$.

The mean duration of the second stage of labor in the paracetamol group was $36.8 \pm 4.0 \mathrm{~min}$ and in the tramadol group was $43.4 \pm 8.6 \mathrm{~min}$. The difference in the mean duration of second stage of labor between the paracetamol and tramadol group was statistically significant $(\mathrm{p}=0.000)$.

The mean duration of third stage of labor in the paracetamol group was $7.2 \pm 1.3 \mathrm{~min}$ and in the tramadol group was $8.4 \pm 2.8 \mathrm{~min}$. The difference in the mean duration of third stage of labor in the two group was statistically significant $(\mathrm{p}=0.000)$.

Total duration of labor from enrolment in study to delivery in the paracetamol group was $280.6 \pm 44.2 \mathrm{~min}$ $(4.67 \pm 0.73 \mathrm{~h})$ and in the tramadol group was $362.5 \pm 42.0$ $(6.0 \pm 0.7 \mathrm{~h})$. The difference in the two groups was significant (p -0.000).

Drug delivery interval in the paracetamol group was $3.0 \pm 1.3 \mathrm{~h}$ and in tramadol group was $3.3 \pm 1.3 \mathrm{~h}$. the difference in the two groups was significant $(\mathrm{p}=0.001)$.

Out of 50.47 women (94\%) in the paracetamol group and 46 women $(92 \%)$ in the tramadol group had spontaneous vaginal delivery. $3(6 \%)$ women in the paracetamol group and $4(8 \%)$ women in the tramadol group had to undergo LSCS. There was no instrumental vaginal delivery in both groups. No statistically significant difference in the mode of delivery was found between the two groups ( $\mathrm{p}=0.580)$.

The mean Apgar score of neonates in the paracetamol group at $1 \mathrm{~min}$ was $7.7 \pm 1.2$ at $5 \mathrm{~min}$ was $9.6 \pm 0.8$. The mean Apgar score of the neonates in the tramadol group at I min was $7.8 \pm 1.2$ and at $5 \mathrm{~min}$ was $9.7 \pm 0 . \mathrm{j}$. The difference was statistically insignificant $(\mathrm{p}=0.636,0.204)$.

In the paracetamol group, nausea was seen in $2.2 \%$ followed by vomiting in $1.1 \%$. Nausea was the most common side effect in tramadol group (6.4\%) followed by vomiting $(4.3 \%)$. The differences in the nausea and vomiting were statistically insignificant between the two groups $(\mathrm{p}=0.157,0.182)$. No women in the paracetamol group had respiratory depression, PPH, fetal tachycardia/bradycardia.

\section{DISCUSSION}

The analgesic action of IV paracetamol is peripheral and central inhibition of Cox and/or serotonergic system. $1 \mathrm{~g}$ of IV paracetamol should only be given when weight is more than $33 \mathrm{~kg}$, and hepatic disorders are ruled out. it should not be repeated within $4 \mathrm{hrs}$ and must not exceed $4 \mathrm{~g}$ in $24 \mathrm{hrs}$ tramadol is a pethidine like synthetic opioid having low affinity for opioid receptors and unlike other opioid, it inhibits reuptake of noradrenaline and 5HT-1. ${ }^{4}$ It has no clinically significant respiratory depression at usual doses of 1-2 $\mathrm{mg} / \mathrm{kg}$ body wt. however concerns have been voiced over high placental permeability of tramadol and side effects like nausea, vomiting and delayed gastric emptying which could lead to risk of aspiration in case general anaesthesia required in an emergency situation.

The findings of present study suggest that paracetamol group had a significant decrease in pain intensity 1 and 3 hrs after intravenous paracetamol administration as compared to intramuscular tramadol group.

About $75 \%$ women in paracetamol group had substantial relief of pain which lasted $3 \mathrm{hrs}$. This might be explained by the fact that peak analgesic effect of paracetamol seen at $1 \mathrm{hr}$ and effects last for 4-6 hrs, while intramuscular tramadol onset is within $10 \mathrm{~min}$ and action last for $2-3 \mathrm{hrs}$.

There was a statistically significant reduction in the duration of 1st, 2nd and 3rd stages of labor after administration of intravenous paracetamol, hence total duration of labor was reduced in patients who received paracetamol as compare to tramadol. This could be due to the fact that tramadol causes sedation leading to lesser mobility of women in labor, which could lengthen the labor.

Neonatal outcome was favourable with both paracetamol and tramadol. However side effects like nausea and 
vomiting were observed more in tramadol group but no other major complication occurred with any of the drugs.

\section{CONCLUSIONS}

Findings from the present study demonstrate that intravenous paracetamol is more effective labor analgesic than intramuscular tramadol. Paracetamol also shortens the length of labor and has fewer maternal adverse effects than tramadol; however neonatal outcome of both the drugs is favourable. So from our study we can conclude that intravenous paracetamol is simple, cost effective, feasible option as labor analgesics. In developing countries with low health care resource settings, intravenous paracetamol can be used as a labor analgesic instead of intramuscular tramadol due to its better analgesic action, shortening of labor, and fewer maternal side effects. This was in accordance with the study of Malaise O shows that IV paracetamol has good efficacy and safety in labor analgesia.

Funding: No funding sources Conflict of interest: None declared

Ethical approval: The study was approved by the Institutional Ethics Committee

\section{REFERENCES}

1. Abdollahi MH, Mojibian M, Pishgahi A, Mallah F, Dareshiri S, Mohammadi S. Intravenous paracetamol versus intramuscular pethidine in relief of labor pain in primigravida women. Niger Med J. 2014;54:55-7.

2. Pandya ST. Labour analgesia: recent advances. Indian J Anaesth. 2010;54(5):400-8.

3. Lallar M, Anam HU, Nandal R, Singh SP, Katyal S. Intravenous paracetamol infusion versus intramuscular tramadol as an Intrapartum labor analgesic. J Obstet Gynaecol India. 2015;65(1):1722.

4. Malaise O, Bruyere O, Jean-yves R. Intravenous paracetamol a review of efficacy and safety in therapeutic use. Future Neurol. 2007;2(6):673-88.

Cite this article as: Mohan H, Ramappa R, Sandesh M, Akash BK. Intravenous paracetamol infusion versus intramuscular tramadol as an intrapartum labor analgesic. Int J Reprod Contracept Obstet Gynecol 2015;4:1726-9. 